INOBIS: Jurnal Inovasi Bisnis dan Manajemen Indonesia

Volume 1, Nomor 1, Desember 2017

Aditya Budi Krisnanto

\title{
Strategi Manajemen Hijau Untuk Keunggulan Bersaing Berkelanjutan
}

\author{
Aditya Budi Krisnanto \\ Mahasiswa Program Doktor Manajemen Universitas Brawijaya
}

\begin{abstract}
Abstrak
Dalam era globalisasi, semakin banyak perusahaan-peruahaan berskala besar luar negeri yang masuk ke Indonesia. Kecenderungan ini mengindikasikan persaingan yang semakin tajam.Dalam lingkungan bisnis yang kompetitif, maka perusahaan harus memiliki kemampuan untuk membedakan dirinya dalam persaingan agar dapat mempertahankan kelangsungan hidup perusahaan.Berdasarkan fenomena globalisasi, maka menjadi penting setiap perusahaan untuk memiliki cara berfikir stratejik, dengan menciptakan keunggulan bersaing berkelanjutan (sustainable competitive advantagel SCA), agar dapat menjaga kelangsungan hidup perusahaan dalam persaingan global. Berdasarkan uraian tersebut, maka perlu dikaji Strategi Manajemen Hijau dengan ruang lingkup Greening Business Management kaitannya dalam keunggulan bersaing berkelanjutan.
\end{abstract}

Keywords: Green Business Management, Strategic Management, Competitive advantage

\section{Pendahuluan}

Dalam era globalisasi, semakin banyak perusahaan-peruahaan berskala besar luar negeri yang masuk ke Indonesia. Kecenderungan ini mengindikasikan persaingan yang semakin tajam.Dalam lingkungan bisnis yang kompetitif, maka perusahaan harus memiliki kemampuan untuk membedakan dirinya dalam persaingan agar dapat mempertahankan kelangsungan hidup perusahaan.Berdasarkan fenomena globalisasi, maka menjadi penting setiap perusahaan untuk memiliki cara berfikir stratejik, dengan menciptakan keunggulan bersaing berkelanjutan (sustainable competitive advantagel SCA), agar dapat menjaga kelangsungan hidup perusahaan dalam persaingan global.

Keunggulan bersaing berkelanjutan merupakan arah strategi perusahaan yang bukan merupakan tujuan akhir, tetapi merupakan alat untuk mencapai tujuan perusahaan, yaitu kinerja perusahaan yang menghasilkan keuntungan (profit) relatif tinggi. Keunggulan bersaing berkelanjutan merupakan suatu proses dalam rangka mencapai tujuan organisasi, sehingga perlu pengelolaan dan komitmen manajemen agar selalu unggul dalam persaingan. Keunggulan bersaing berkelanjutan yang terkelola baik melalui cara berfikir manajemen yang selalu merespon dan beradaptasi dengan perubahan, inovasi disegala sisi misalnya produk yang ditawarkan, tehnologi yang digunakanm, atau sistem dan struktur, dengan kesadaran pentingnya pengelolaan lingkungan (greening business), maka organisasi dalam mencapai tujuan menjadi lebih terarah, efektif dan efisien.Greening business adalah lnteraksi antara bisnis dan lingkungan dalam penggunaan sumberdaya alam pada setiap tahapan aktivitas bisnis (Plan-Do-Check- Action), seperti produksi, distribusi, pemasaran, dan konsumsi akhir dari barang dan jasa.Interaksi ini dapat dilihat sebagai simbiosa yang akan memberikan keuntungan bagi kedua belah pihak apabila dilakukan aktivitas positif, yaitu tidak hanya lingkungan yang menjadi sumber eksploitasi tetapi juga bagaimana mengelola dampak lingkungan yang terbentuk akibat aktivitas bisnis. Dengan demikian, perusahaan 
INOBIS: Jurnal Inovasi Bisnis dan Manajemen Indonesia

Volume 1, Nomor 1, Desember 2017

Aditya Budi Krisnanto

yang mengelola strategi bersaingnya dengan unggul dan berkelanjutan dan tidak mengeksploitasi sumber daya alam berlebihan, maka akandapat menghasilkan kinerja yang memberikan value added, karena keunggulan yang dimiliki tidak mudah ditiru atau di substitusi dan berkelangsungan.

Berdasarkan uraian tersebut, maka perlu dikaji Strategi Manajemen Hijau dengan ruang lingkup Greening Business Management kaitannya dalam keunggulan bersaing berkelanjutan.

\section{Kajian Literatur}

\subsection{Green Business Management}

Green business (Business Dictionary, n.d.)is " $a$ business functioning in a capacity where no negative impact is made on the local or global environment, the community, or the economy", selanjutnya ditambahkan bahwa "green business will also engage in forwardthinking policies for environmental concerns and policies affecting human rights". Berbeda pandangan disampaikan G. Croston (2009) yang menyatakan bahwa "Bisnis Hijau memiliki praktek bisnis yang lebih berkelanjutan daripada pesaing, manfaat sistem alam dan membantu orang hidup dengan baik hari ini dan besok, disamping menghasilkan uang dan berkontribusi terhadap perekonomian". Sedangkan Markower dan Pyke (2009) berpandangan bahwa"a green business requires a balanced commitment to profitability, sustainability and humanity" Pandangan berbeda disampaikan Slovik, (2013) "A "green business" didefinisikan sebagaiorganisasi yang menggunakan sumber daya terbarukan (lingkungan berkelanjutan) dan memegang sendiri tanggung jawab untuk aspek sumber daya manusia dari kegiatan yang dijalankan (tanggung jawab sosial) ".Berdasarkan berbagai pandangan tersebut maka dapat didefinisikan green businessadalah sebuah organisasi yang dalam organisasinya berkomitmen untuk prinsip-prinsip kelestarian lingkungan, berusaha untuk menggunakan sumber daya terbarukan, dan mencoba untuk meminimalkan dampak negatif terhadap lingkungan dari kegiatannya. Kassaye, (2001) berpandangan bahwa partisipasi mengelola green business berimplikasi pada "4Rs" yaitu reduction, reuse, recycling, and recovery. $R$ disini, memiliki arti ganda: sebagai pengurangan konsumsi sumber daya dan pengurangan limbah. Untuk contoh: Sebuah kesadaran lingkungan pada pengurangan konsumsi energi,misalnya, dengan mengganti lampu pijardengan lampu hemat energi, atau hanya dengan mematikan peralatan elektronik ketika tidak digunakan.

Green Management bukanlah sebuah konsep yang menggambarkangaya manajemen bisnis baru. Green Management menggambarkan konstruksi (tepatnya proses konstruksi) dari bisnis.Green Management merupakan suatu metode yang menghasilkan keuntungan. Green Management (Siddhant, 2013, 5695) adalah tanggung jawab sosial perusahaan di seluruh dunia mulai hari ini, karena berbagai alasan yang mempengaruhi manusia dan lingkungan.

Berdasarkan pandangan-pandangan tersebut, maka dalam paper ini dapat diartikan Green Business Management adalah strategi pengelolaan lingkungan yang terpadu yang meliputi pengembangan struktur organisasi, sistem dan budidaya dalam suatu kompetensi hijau dengan cara menerapkan dan mentaati seluruh peraturan tentang pengelolaan lingkungan, termasuk pengelolaan bahan baku, pengolahan limbah, penggunaan sumberdaya alam yang efektif, penggunaan teknologi produksi yang menghasilkan limbah minimal serta menerapkan komitmen kesadaran lingkungan bagi seluruh karyawan dalam organisasi. 
INOBIS: Jurnal Inovasi Bisnis dan Manajemen Indonesia

Volume 1, Nomor 1, Desember 2017

Aditya Budi Krisnanto

Kepedulian industri pada lingkungan sebagai aspek yang penting dalam usaha karena beberapa hal :

1. Lingkungan dan efisiensi,

Sumber daya alam sangat terbatas, oleh sebab itu industri harus mengupayakan daur ulang dan melakukan efisiensi dalam penggunaan setiap material dan energi dalam proses produksi, yang mana hal tersebut mempunyai implikasi pada pengurangan biaya produksi, dan limbah yang minimal.

2. "Image" lingkungan,

Sikap positif perusahaan melalui manajemen yang empati terhadap lingkungan merupakan suatu hal yang baik untuk dapat menumbuhkan "image" dan reputasi perusahaan itu sendiri.

3. Lingkungan dan peluang pasar,

Kesadaran mendaur ulang dan meminimalkan limbah mendorong tumbuhnya bisnis dalam bidang pengolahan limbah, peralatan pengendalian pencemaran udara, teknologi daur ulang, desain "containers" kemasan merupakan suatu peluang pada pengelolaan lingkungan dari strategi "end-off pipe treatment' menjadi "waste reduction at source".

4. Ketaatan terhadap peraturan lingkungan,

Aktivitas perusahaan yang berbasis lingkungan, maka perusahaan akan menciptakan sistem input, proses dan output yang terintegrasi sehingga memungkinkan tercapainya suatu perusahaan hijau secara komprehensif. Sony, Ferguson dan Beise-zee (2015) menyatakan perusahaan yang hijau karena faktor regulasi, perusahaan yang membuat produk hijau, perusahaan yang melakukan strategi pemasaran hijau hubungan sebab akibat, dan perusahaan yang membuat produk hijau serta memasarkan hubungan sebab akibat menerapkan green strategy, konsumen sangat memberikan penghormatan yang besar terhadap perusahaan yang membuat produk hijau dan memasarkan hubungan sebab akibatnya.

Green business management menjadi keharusan bagi manajemen dalam menjalankan usahanya karena memiliki beberapa manfaat :

1. Mengurangi biaya operasi dengan mengefisiensikan eksploitasi sumber daya alam yaitu dengan mengurangi jumlah limbah yang terbentuk, memaksimumkam konservasi energi, melakukan daur ulang dan memperpanjang siklus bahan baku yang digunakan.

2. Menciptakan keunggulan bersaing dan dapat mempertahankan kesetiaan pelanggan, karena dapat memenuhi keinginan pelanggan akan produk dan kemasan yang ramah lingkungan.

3. Dapat menciptakan strategi lingkungan yang unik dan sukar untuk ditiru, sehingga menjadi perusahaan yang berbeda dan menjadi pemimpin dalam perusahaan berwawasan lingkungan.

4. Membantu perusahaan melakukan ekspansi ke pasar global.

5. Meningkatkan "image" perusahaan dan hubungan baik dengan masyarakat.

6. Memperkecil resiko lingkungan jangka panjang yang berkaitan dengan kerusakan sumber daya alam, konservasi energi dan pengendalian pencemaran serta pengelolaan limbah.

7. Memberikan keuntungan bagi ekosistem dan komunitas dimana perusahaan itu beroperasi. 
INOBIS: Jurnal Inovasi Bisnis dan Manajemen Indonesia

Volume 1, Nomor 1, Desember 2017

Aditya Budi Krisnanto

8. Dipandang dari sudut etika merupakan sesuatu yang sangat diinginkan dan tidak dapat dihindari.

9. Menjadikan perusahaan selangkah lebih maju dalam mentaati peraturan lingkungan.

Menyimak manfaat tersebut, maka beberapa hal perlu diperhatian dalam green business management:

1. Mengembangkan produk, kemasan dan sistem operasi sesuai dengan sumber daya alam yang tersedia,

2. Melakukan pemilihan lokasi fasilitas produksi yang dapat meminimumkan tranportasi dalam setiap aktivitasnya serta mengupayakan penggunaan sumber daya alam yang dapat diperbaharui (renewable).

3. Menggunakan teknologi yang dapat menggunakan sumber daya alam setempat dan hemat energi serta seminimal mungkin menghasilkan limbah.

4. Mengimplementasikan standar lingkungan, keselamatan kerja dan kesehatan yang biasa digunakan secara internasional maupun lokal.

5. Menyebarluaskan teknologi dan manajemen berwawasan lingkungan pada seluruh perusahaan diseluruh dunia terutama pada negara-negara berkembang.

6. Menciptakan "safety zone" yang dilengkapi dengan fasilitas infrastruktur untuk mendukung operasi perusahaan.

\subsection{Green Strategic Management}

Pearce Dan Robinson (1988, p. 6) mendefinisikan manajemen strategis sebagai, 'the set of decisions and actions resulting in formulation and implementation of strategies designed to achieve the objectives of an organization.' Certo Dan Peter (1990) mendefinisikan manajemen strategis sebagai, suatu proses yang berulang terus menerus bertujuan untuk menjaga sebuah organisasi secara keseluruhan tepat sesuai dengan lingkungannya. Ditambahkan bahwa Manajemen strategis berkaitan dengan mendefinisikan kinerja organisasi, variabel pilihan strategis, dan keunggulan bersaing.

Maier and Remus $(2002,110)$ menggunakan terminology strategi sumber daya dan menentukan tiga langkah dalam penciptaan strategi sumber daya perusahaan yaitu competence creation, competence realisation and competence transaction. Competence creation mendefinisikan dan menganalisis pasar, produk dan layanan.Competence realization melibatkan pelaksanaan layanan, pengadaan, dan produksi. Competence transaction melibatkan logistik pasar, pemenuhan pesanan dan pemeliharaan.

Green Strategic Management/GSM atau Manajemen strategi hijau bermakna sama sebagaimana manajemen strategi yanglain. Penambahan kata 'hijau' berarti komponen dengan prosedur konvensional yangmemasukkan praktek-praktek seperti operasi hijau, desain hijau, manufaktur hijau, reverse logistik, dan pengelolaan limbah. Sebagaimana strategi manajemen, maka GSM juga meliputi formulasi dan implementasi serta monitoring.Pada tahapan formulasi adalah mengelola tujuan dengan mengidentifikasi tujuan yang relevan dan spesifikasi dari rencana jangka panjang.Sebagaimana pandangan GSM (Padash, 2015, 260) mendefinisikanas 'integrating environmental, health and safety (EHS) toward sustainable developing. Lebih lanjut menambahkan dalam mengukur kinerja instrumen yang perlu diperhatikan adalah prosedur manajemen, termasuk desain produk, sumber bahan dan seleksi, proses manufaktur, pengiriman produk akhir ke konsumen, serta end-of-life manajemen produk setelah masa pakai.Selanjutnya dengan dukungan manajemen 
INOBIS: Jurnal Inovasi Bisnis dan Manajemen Indonesia

Volume 1, Nomor 1, Desember 2017

Aditya Budi Krisnanto

pada tahapan implementasi GSM meliputi pendistribusikan kebijakan agar perhatian orang bertanggung jawab dan menghubungkan mereka pada tujuan mereka (secara terukur), memonitor pelaksanaannya secara terus menerus dan memberikan dukungan terus-menerus sampai hasil positif yang diperoleh, memberikan informasi tentang semua aspek agar bekerja dengan transparansi,dan tindakan harus dilakukan oleh sumber daya yang dibutuhkan untuk menyelesaikan aktivitas dengan target waktu. Secara lengkap Green Strategic Management terdiri dari beberapa tahap (Siddhant, 2013) yaitu menentukan model yang dibutuhkan untuk kegiatan pengembangan berkelanjutan (Tahap 1), Mulai bekerja dengan mengurangi limbah danpolusi, melestarikan sumber daya dan untuk meningkatkan respon sosial (Tahap 2), Memahami agenda green management secara menyeluruh (Tahap 3), Memformulasi perencanaan green management (Tahap 4), Implementasi Green Management (Tahap 5), dan Monitoring pelaksanaan green management (Tahap 6). Penerapan green strategy dapat membuat perusahaan memiliki keunggulan bersaing (Abdelzaher dan Newburry, 2016).

\subsection{Sustainable Competitive Advantage}

Competitive advantageatau keunggulan bersaing adalah yang tidak mudah ditiru atau di lampaui pesaing.Konsep sustainable competitive advantage (SCA) telah diperkenalkan pada tahun 1984 saat Day menjelaskan strategi mempertahankan competitive advantage. Sustainable competitive advantage berkembang pada tahun 1985 oleh Porter (1985; 12), yang mendefinisikan SCA sebagai "the fundamental basis of above-average performance in the long run". Pandangan yang hampir samaoleh Hill and Jones $(2004 ; 76)$ an organisation "has a sustained competitive advantage when it is able to maintain above-average profitability over a number of years". Fiol $(2001 ; 692)$ berpendapat bahwa "the skills/resources and the way organisations use them must constantly change, leading to the creation of continuously changing temporary advantages".

Sustainable competitive advantage (Coyne Kevin, 1986) dipengaruhi oleh tiga faktor yaitu ukuran target pasar, akses terhadap sumber daya dan pelanggan, dan pembatasan kekuasaan pesaing. Perusahaan dapat menciptakan keunggulan bersaing yang berkelanjutan jika manajer menerapkan strategi berdasarkan karakteristik yang tidak dapat dengan mudah ditiru, dan sumber daya perusahaan yang tidak dapat diakses oleh para pesaing. Dengan demikian keunggulan bersaing berkelanjutan (SCA) berdasarkan berbagai pandangan tersebut dilakukan melalui struktur relasional, reputasi, inovasi, dan aset strategis. Aspek yang perlu dikembangkan untuk mencapai korporasi/bisnis yang berkelanjutan adalah sebagai berikut:

1. Memperluas misi dari kinerja berwawasan ekologi sehingga menjadi suatu bisnis berkelanjutan secara ekologi.

2. Memperkenalkan program pengelolaan lingkungan yang komprehensif dan terintegrasi yaitu strategic product, sistem produksi dan pelaksanaan pengelolaan limbah yang aman lingkungan, selanjutnya ditetapkan sebagai prioritas utama korporat.

3. Berperan aktif dalam menyelesaikan masalah lingkungan global untuk mencapai pembangunan berkelanjutan, yang meliputi keamanan produk yang dikonsumsi oleh manusia (makanan), proteksi ekosistem, mengurangi populasi dan konservasi energi dan sumberdaya alam.

4. Meningkatkan kebijaksanaan, program dan kinerja yang berwawasan lingkungan untuk dapat memenuhi keinginan konsumen dan masyarakat yang telah sadar lingkungan. 
INOBIS: Jurnal Inovasi Bisnis dan Manajemen Indonesia

Volume 1, Nomor 1, Desember 2017

\section{Aditya Budi Krisnanto}

5. Mengedukasi seluruh karyawan agar mempunyai motivasi bertanggungung jawab terhadap lingkungan dalam melaksanakan setiap aktivitasnya.

6. Membuat penilaian tentang, dampak lingkungan yang akan ditimbulkan oleh suatu proyek baru sebelum aktivitas berjalan.

7. Mengembangkan produk dan jasa yang aman bagi lingkungan, efisien dalam penggunaan energi dan sumber daya alam dan dimungkinkan untuk didaur ulang atau dibuang secara aman.

8. Mengembangkan fasilitas dan operasi dengan menggunakan sumber daya alam yang dapat diperbaharui, meminimumkan dampak dan limbah yang dihasilkan serta merencanakan pembuangan akhir residu limbah yang aman lingkungan.

9. Melakukan penelitian-penelitian yang berkaitan dengan bahan baku, proses, produk, kemasan, pengelolaan limbah, transportasi, distribusi dalam rangka ecoefficiency.

10. Melakukan modifikasi proses, pemasaran atau penggunaan produk yang dapat mencegah kerusakan lingkungan.

11. Mendorong kontraktor dan supplier dalam mengembangkan bisnis berwawasan lingkungan.

12. Mengembangkan dan mencegah terlepasnya B3 ke lingkungan dengan menerapkan chemical management.

13. Mengkontribusikan teknologi dan metode manajemen berwawasan lingkungan melalui industri dan sektor publik.

14. Mengkontribusikan pengembangan kebijakan dan program-program bisnis untuk meningkatkan kesadaran dan proteksi terhadap lingkungan.

15. Menjadi mediator dalam dialog dengan masyarakat dan karyawan dalam mengantisipasi dan merespon hal-hal yang berkaitan dengan bahan baku yang berpotensi B3 serta dampaknya terhadap operasi, produk, limbah dan perpindahan lintas batas.

16. Mentaati semua peraturan yang berkaitan dengan aspek lingkungan dan secara rutin membuat laporan pelaksanaannya untuk disampaikan pada institusi yang berwenang.

\section{Pembahasan}

Teori manajemen yang membantu studi keberlanjutan usaha adalah kontinjensi. Karena teori kontinjensi dapat mengeksplorasi situasi dengan memilih antara kooperasi dan persaingan, eksploratori dan eksploitasi. Keunggulan bersaing berkelanjutan merupakan masalah bagi tiap bisnis dalam skala apapun. Skala bisnis kecil, menengah dan besar samasama menghendaki bisnisnya terus berlangsung, untuk dapat berlangsung maka harus memiliki keunggulan diantara pesaing. Keunggulan ini harus terus menerus di improve dari waktu ke waktu seiring perubahan lingkungan baik lingkungan internal dan lingkungan eksternal yang tidak jarang menimbulkan konflik antara shareholders, customers, employees, communities and suppliers. Namun, persoalan yang tidak perlu lagi diperdebatkan adalah bisnis dijalankan dengan menyadari keterbatasan sumber daya dibanding dengan permintaan untuk memenuhi kebutuhan dengan menjalankan bisnis hijau (Business Green Management). Sebagai contoh, bahwa alam Indonesia dengan luasnya daerah perairan, maka dimanjakan dengan hasil pohon kelapa.Pohon-pohon kelapa tumbuh dengan sendirinya di pantai, tidak merasa bahwa perusahaan menanam, namun pohon kelapa telah memberikan kemanfaatan yang besar bagi manusia.Pada akhirnya pebisnis melihat banyak peluang usaha dan membesarkannya menjadi industri. Buah kelapa menjadi santan yang telah diolah dalam bentuk kemasan cair maupun bubuk atau minyak kelapa yang sangat banyak manfaatnya 
INOBIS: Jurnal Inovasi Bisnis dan Manajemen Indonesia

Volume 1, Nomor 1, Desember 2017

Aditya Budi Krisnanto

diantaranya untuk menyuburkan rambut, jika minyak dibakar maka dapat dijadikan obat luka, batok kelapa dimanfaatkan sebagai bahan bakar rumah tangga atau kerajinan rakyat mendukung pariwisata berbasis bahan baku lokal, sedangkan daun kelapa muda dapat dimanfaatkan untuk pembungkus ketupat, hiasan pesta hajatan, atau acara ritual keagamaan, sedangkan yang sudah tua dapat diambil batangnya menjadi lidi untuk menyapu halaman tanah, pohonnya dapat digunakan untuk perabotan atau hiasan. Hal ini adalah contoh lama dalam mengelola bisnis berbasis sumber daya alam. Pertanyaannya, sudahkah industri berfikir strategis bahwa sumber daya alam ini semakin berkurang cability nya, lingkungan pantai terganggu karena pohon kelapa banyak yang dimanfaatkan, limbah kelapa yang tidak aman karena tidak bisa mengurai sendiri seperti serabut kelapa yang diambil kelapa dan batoknya, demikian juga dengan air kelapa yang dibuang begitu saja. Dengan demikian proses bisnis tersebut berdampak pada EHSE yaitu environment (lingkungan), health (sehat), Safety (aman), dan Energy (daya).

Bisnis yang berorientasi unggul berkelanjutan menyadari keadaan ini harus dibenahi. Sebagaimana mengelola bisnis hijau, maka akan memperoleh peluang revenue dengan melakukan re use, recovery, recycle dan reduction. Akibatnya, dalam jangka panjang perusahaan dapat menghemat biaya dari hasil reuse dan recycling (Kirchoff, Tate, dan Mollenkopf, 2016). Maka, limbah serabut kelapa yang seolah tidah memberi guna di daur ulang (recycle) menjadi kerajinan keset, limbah parutan kelapa yang telah diambil santannya dimanfaatkan kembali menjadi kudapan serundeng, begitu juga dengan air kelapa yang tadinya banyak terbuang dimanfaatkan kembali menjadi campuran nata de coco (re use). Sudah barang tentu, berkembangnya usaha baru dari limbah yang ada telah menciptakan lapangan kerja dan menghasilkan pendapatan, serta dapat menurunkan pemborosan karena tidak banyak hasil yang terbuang percuma (reduction). Perusahaan yang mampu memanfaatkan sumber daya mulai dari hilir ke hulu, dapatmencapai keuntungan ekonomi (revenue).Namun secara sosial belum, karena masih diperlukan tindakan recovery berupa menanam tunas-tunas kelapa baru menggantikan yang telah dimanfaatkan sehingga ekosistem pantai tetap terjaga dan para penerus kehidupan dapat menemukan dan memanfaatkan warisan sumber daya alam pohon kelapa.

Mengelola bisnis hijau sebagai keunggulan bersaing berkelanjutan dengan mengamankan limbah agar lingkungan sehat memerlukan proses, yang diawali dari tahapan merencanakan formulasi inovasi pemanfaatan limbah atau menjaga kuantitas pohon, selanjutnya memilih mana yang menjadi prioritas dan dituangkan dalam program kerja dan anggaran yang dibutuhkan. Setelah strategi formulasi disusun selanjutnya diimplementasikan disertai melakukan monitoring agar formulasi yang sudah dirumuskan tetap dapat berjalan sesuai arah untuk mencapai keunggulan berkelanjutan, karena tidak mudah ditiru dan digantikan serta memiliki nilai tambah sehingga konsumen berniat membeli produk tersebut. Menurut Borin, Mullikin, Khrisnan (2013) menyebutkan konsumen percaya membeli produk yang hijau dari perusahaan yang menerapkan green strategy dapat membantu permasalahan lingkungan dan dapat menjadi sebuah tren agar perusahaan lebih peduli terhadap lingkungan.

Dengan demikian keseluruhan tindakan Green Strategic Management merupakan perwujudan rasa syukur atas pemberian Tuhan berupa pohon kelapa yang tidak sulit menanam dan merawatnya, tetapi memberikan manfaat yang sangat besar secara ekonomi dan sosial.Strategi manajemen hijau perlu mengubah proses bisnis untuk mengurangi dampak pada EHSE (environment, health, safety, dan energy), untuk operasi end-to-end, melalui penggunaan sistem "smart" (specific, measurable, accurate, reliable, timely), peningkatan efisiensi yang dramatis dapat terjadi. Ketika berbisnis dengan berlandaskan KeTuhanan, 
INOBIS: Jurnal Inovasi Bisnis dan Manajemen Indonesia

Volume 1, Nomor 1, Desember 2017

Aditya Budi Krisnanto

bersyukur, dan tetap menjaga keseimbangan alam, lingkungan dan manusia, maka akan memperoleh keberkahan yang luas dari bisnis yang dikelola serta reputasi dan terpercaya.

\section{Kesimpulan}

Berdasarkan latar belakang, kajian literature dan pembahasan tersebut, maka dapat disimpulkan untuk paper ini :

1. Green strategic Management adalah kegiatan manajemen dalam menghasilkan keuntungan dengan berkomitmen pada prinsip-prinsip kelestarian lingkungan, berusaha untuk menggunakan sumber daya terbarukan, dan mencoba untuk meminimalkan dampak negatif terhadap lingkungan,agar tercipta citra perusahaan melalui recycle, reduce, re use dan recovery.

2. Sustainable Competitive Advantage adalah proses mempertahankan kinerja jangka panjang dengan dukungan manajemen, memformulasi rencana keunggulan bersaing, implementasi dan evaluasi secara terus menerus dan berkelanjutan, melalui inovasi yang tidak mudah ditiru, disubstitusi dan memiliki value added.

3. Green strategic Management dengan indikator recycle, reduce, re use dan recoveryberpengaruh terhadap Sustainable competitive Advantage dengan indikator tidak ditiru,tidak ada substitusi dan memiliki nilai tambah berimplikasi pada citra perusahaan dengan indikator reputasi dan credible.

\section{Referensi}

Abdelzaher, D., Newburry, W., (2016), “Do green policies build green reputations?", Journal of Global Responsibility, Vol. 7 lss 2 pp. 226-246

Borin, N., Mullikin, J. L., Krishnan, R., (2013), “An analysis of consumer reactions to green strategies", Journal of Product \& Brand Management, Vol. 22 lss 2 pp. 118-128

Certo, SC\& Peter, JP.,(1990), Strategic Management: A Focus on Process, McGraw-Hill, New York.

Coyne, K. P.(1986). "Sustainable Competitive Advantage -What it is, What it isn"t", Business Horizons, January/ February.

Fiol, C. Marlene. (2001). "Revisiting an identity-based view of sustainable competitive advantage", Journal of Management,No. 27, p. 691-699

Hill, C.W., Jones, G.R. (2004), "Strategic Management: An Integrated Approach", Houghton, Mifflin Company, Boston, MA.

Kay, J., (1995). Why firms succeed. Oxford: Oxford University Press

Kirchoff, J. F., Tate, W. L., Mollenkopf, D. A., (2016), "The impact of strategic organizational orientations on green supply chain management and firm performance", International Journal of Physical Distribution \& Logistics Management, Vol. 46 lss 3 pp. 269-292

Maier, R \& Remus, U.,(2002), 'Defining process-oriented knowledge management strategies',Knowledge and Process Management, vol.9,no.2, p.103-118.

Padash, A.M, Khodaparast, A. Zahirian and A. Kaabi Nejadian, (2011), Green Sustainable Island by Implementation of Environmental, Health, Safety and Energy Strategy in KISH Trading-Industrial Free Zones-IRAN, Proceeding World Renewable Energy Congress.Sweden, p.3034. 
INOBIS: Jurnal Inovasi Bisnis dan Manajemen Indonesia Volume 1, Nomor 1, Desember 2017

Aditya Budi Krisnanto

Padash,A.M, Gh.N. Bidhendi, H. Hoveidi, M. Ardestani, (2015), Green strategy management framework towards sustainable development, Bulgarian Chemical Communications, Volume 47, Special Issue D, p. 259 - 268

Pearce, JA\& Robinson, RB., (1988), Strategic Management: Strategy Formulation and Implementation, $3^{\text {rd }}$ end, Irwin.

Porter, M.,(1985), Competitive advantage: Creating and sustaining superior performance.New York: Free Press.

Porter, M.E., van der Linde, C., (1995). Green and competitive: ending the stalemate. Harvard Business Review, vol. 73. No.5, p.120-134

Porter, ME, (1996), 'What is Strategy?' Harvard Business Review, vol. 74, no.6, p. 61-78.

Siddhant Umesh Sawant, Rithwick Mosalikanti, Rahul Jacobi, Sai Prasad Chinthala, B Siddarth, (2013), Strategy for Implementation of Green Management System to Achieve Sustainable Improvement for Eco friendly Environment, Globally, International Journal of Innovative Research in Science, Engineering and Technology, Vol. 2, Issue 10, p. 5695-5701

Sony, A., Ferguson, D., Beise-zee, R., (2006), "How to go green: unraveling green preferences of consumers", Asia-Pacific Journal of Business Administration, Vol. 7 lss 1 pp. 56-72

Srivastava, Samir, (2007), Green supply-chain management: A state-of-the-art literature review, International Journal. Management Review, Vol. 9, 1, p. 53-80 